\title{
Effect of Trichostatin A on Anti HepG2 Liver Carcinoma Cells: Inhibition of HDAC Activity and Activation of Wnt/ $\beta$-Catenin Signaling
}

\author{
Qing-Qiang Shi ${ }^{1}$, Guo-Wei Zuo², Zi-Qiang Feng ${ }^{1}$, Lv-Cui Zhao ${ }^{1}$, Lian Luo ${ }^{1}$, Zhi- \\ Mei You ${ }^{1}$, Dang-Yang $\mathrm{Li}^{1}$, Jing $\mathrm{Xia}^{1}$, Jing $\mathrm{Li}^{1 *}$, Di-Long Chen ${ }^{1 *}$
}

\begin{abstract}
Purpose: To investigate the effect of deacetylase inhibitory trichostatin A (TSA) on anti HepG2 liver carcinoma cells and explore the underlying mechanisms. Materials and Methods: HepG2 cells exposed to

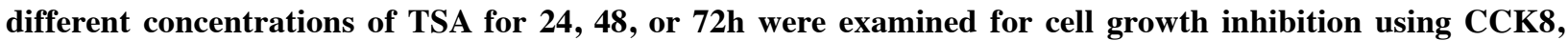
changes in cell cycle distribution with flow cytometry, cell apoptosis with annexin V-FTIC/PI double staining, and cell morphology changes under an inverted microscope. Expression of $\beta$-catenin, HDAC1, HDAC3, H3K9, CyclinD1 and Bax proteins was tested by Western blotting. Gene expression for $\beta$-catenin, HDAC1and HDAC3 was tested by q-PCR. $\beta$-Catenin and H3K9 proteins were also tested by immunofluorescence. Activity of Renilla luciferase (pTCF/LEF-luc) was assessed using the Luciferase Reporter Assay system reagent. The activity of total HDACs was detected with a HDACs colorimetric kit. Results: Exposure to TSA caused significant dose-and time-dependent inhibition of HepG2 cell proliferation $(p<0.05)$ and resulted in increased cell percentages in G0/ G1 and G2/M phases and decrease in the $S$ phase. The apoptotic index in the control group was $6.22 \pm 0.25 \%$, which increased to $7.17 \pm 0.20 \%$ and $18.1 \pm 0.42 \%$ in the treatment group. Exposure to 250 and $500 \mathrm{nmol} / \mathrm{L}$ TSA also caused cell morphology changes with numerous floating cells. Expression of $\beta$-catenin, H3K9and Bax proteins was significantly increased, expression levels of CyclinD1, HDAC1, HDAC3 were decreased. Expression of $\beta$-catenin at the genetic level was significantly increased, with no significant difference in HDAC1and HDAC3 genes. In the cytoplasm, expression of $\beta$-catenin fluorescence protein was not obvious changed and in the nucleus, small amounts of green fluorescence were observed. H3K9 fluorescence protein were increased. Expression levels of the transcription factor TCF werealso increased in HepG2 cells following induction by TSA, whikle the activity of total HDACs was decreased. Conclusions: TSA inhibits HDAC activity, promotes histone acetylation, and activates Wnt/ $\beta$-catenin signaling to inhibit proliferation of HepG2 cell, arrest cell cycling and induce apoptosis.
\end{abstract}

Keywords: HepG2 cells - TSA - apoptosis - HDAC - $\beta$-catenin - histone acetylation

Asian Pac J Cancer Prev, 15 (18), 7849-7855

\section{Introduction}

Hepatic carcinoma, one of the most common malignant tumor in China, was found later (Quint et al., 2011; Chen et al., 2014; Page et al., 2014; Scaggiante et al., 2014). The incidence of HCC is increasing, particularly in China, due to the high prevalence of hepatitis virus infection, which confers a high risk of HCC (Ji et al., 2014; Li et al., 2014). Despite advances in diagnosis and treatment, HCC remains the third leading cause of cancerassociated mortality worldwide (Haghshenas et al., 2014; Scaggiante et al., 2014). Surgical resection is the most effective treatment for the majority of HCC patients, but the overall five year survival rate remains $<12 \%$. Surgical resectionIand VII section of Hepatic carcinoma is very difficult, so vast of patients lost the opportunity to surgery (Xu, 2010; Ker et al., 2011; Tanase et al., 2014). With the development of interventional treatment, chemotherapy drugs can directionally target hepatic carcinoma cells, which can prolong the life of patients with liver cancer (Osaki et al., 2013; Lee et al., 2014; Miyahara et al., 2014; Scaggiante et al., 2014; Tsai et al., 2014). However, certain percentage of hepatic carcinoma patients is not sensitive to chemotherapy and prone to resistance (Pathil et al., 2006). For most patients with liver cancer, it is lack of effective treatment. Therefore, seeking effective drugs to improve the effect of cancer chemotherapy is a focus of research.

Cancer epigenetics research shows that histone acetylation or deacetylation involved in tumorigenesis and affected gene expression and so on (Marks et al., 2001; 
Fujisawa et al., 2005; Yang and Seto, 2007; Ying and Tao, 2009). Histone deacetylases (HDACs) play an important role in the epigenetic regulation of gene expression by catalyzing the removal of acetyl groups, stimulating chromatin condensation, and promoting transcriptional repression. Since aberrant epigenetic changes are a hallmark of cancer, HDACs appear to be a promising target for pharmacological inhibition. Due to a particular resistance against conventional chemotherapeutics, palliative treatment of hepatocellular carcinomas (HCC) is highly ineffective. Effective treatment for hepatocellular carcinoma is urgently needed. Recent studies showed that histone deacetylase inhibitor displayed growth-inhibitory and apoptosis-inducing effect of hepatoma cells. It prompted a new therapeutic method to hepatoma.

Jeanette Wiltse reported that deacetylated histone transferase inhibitor can activate the Wnt/ $\beta$-catenin signaling pathway and change gene expression depending on the $\mathrm{Wnt} / \beta$-catenin signaling pathways (Wiltse, $2005)$. Wnt/ $\beta$-catenin signaling pathways involved in the formation of the colorectal cancer, leukemia, breast cancer (Lazarova et al., 2004; Woo et al., 2007; Debeb et al., 2012). Recent data suggested that $\mathrm{Wnt} / \beta$-catenin signaling pathway played a key role in liver cell growth, differentiation and regeneration (Dahmani et al., 2011), but the abnormalities signal were closely associated with liver cancer (Cui et al., 2001; Thompson and Monga, 2007; Miyoshi et al., 2009).

Deacetylation transferase inhibitor (Trichostatin A, TSA) effected on leukemia, stomach cancer, cervical cancer, prostate cancer, liver cancer, lung cancer, pancreatic cancer and neuroblastoma tumor cells can obviously inhibit proliferation, differentiation and promote apoptosis (Woo et al., 2007; Zhang et al., 2012; Song et al., 2013), its mechanism is not fully clear, but opens up new way for tumor treatment (Myzak et al., 2004). It is important to illuminate the concrete mechanism of TSA on liver cancer, which is vital to clinical experimental research.

\section{Materials and Methods}

\section{Cell culture}

HepG2 cells (Bogoo, Shanghai, China) were cryopreserved in our laboratory, cultured in DMEM-F12 medium containing $10 \%$ fetal bovine serum (HyClone, Waltham, MA, USA), at $37^{\circ} \mathrm{C}$ in air- $5 \% \mathrm{CO}_{2}$ incubator at constant humidity.

\section{Antibodies and chemicals}

TSA purchased from Sigma company, purity 99\%; Cell Counting Kit-8 (Takara Bio, Inc., Shiga, Japan); Annexin V-FITC notation apoptosis detection kit (KeyGEN Biotech co., Shanghai, China); The primary antibodies:HDAC1 (1:1000), HDAC3 (1:1000)antibody purchased from Cell Signaling Technology (Danvers, MA, USA); $\beta$-catenin (1:1000), Bax (1:1000), CyclinD (1:1000) antibody purchased from Sigma company. Luciferase Reporter Assay system reagent purchased from TaKaRa . HDACs Colorimetric kit purchased from Cell Signaling Technology (Danvers, MA, USA) .The secondary antibodies: horseradish peroxidase (HRPconjugated goat anti-rabbit IgG antibody, HRP-conjugated goat anti-mouse IgG antibody (Beyotime Institute of Biotechnology, Shanghai, China).

\section{CCK-8 assay}

For cell proliferation, a CCK-8 assay was done. Briefly, $1 \times 10^{4}$ cells per well were plated in 96-well plates and cultured for different times. At the end of time, 20 $\mu \mathrm{l}$ CCK-8 was added to each well and then incubated at $37^{\circ} \mathrm{C}$ for $3 \mathrm{~h}$. Then plates were detected by $450 \mathrm{~nm}$ on a spectrophotometric plate reader (Shanghai Precision and Scientific Instrument Co., Ltd., Shanghai, China).

\section{Cell morphology and imaging}

Logarithmic growth of HepG2 cells with $1 \times 10^{6}$ cells $/ \mathrm{ml}$ were seeded, the drug group were added TSA indifferent concentrations $(250,500 \mathrm{nmol} / \mathrm{L})$, and control group added DMSO, incubated $24 \mathrm{~h}, 48 \mathrm{~h}, 72 \mathrm{~h}$, respctively, Cell morphology were observed by inverted microscope and photographed (Shanghai Optical Instrument Factory, Shanghai, China).

\section{Cell cycle assay}

The cells were seeded at a concentration of $2 \times 10^{5}$ cells $/ \mathrm{ml}$ and incubated for $24-72 \mathrm{~h}$ with TSA at various concentrations. TSA dissolved in dimethyl sulfoxide was added to the medium in serial dilution. The cells were collected by centrifugation at 2500 r.p.m. for $5 \mathrm{~min}$, fixed in $70 \%$ ethanol then washed once with PBS and resuspended in $1 \mathrm{ml}$ of PBS containing $2.5 \mu \mathrm{g} / \mathrm{ml}$ ribonuclease and $50 \mu \mathrm{g} / \mathrm{ml}$ propidium iodide (Beyotime Institute of Biotechnology, Shanghai, China), incubated in the dark for $30 \mathrm{~min}$ at room temperature and analyzed using flow cytometry (FCM).

\section{Apoptosis}

Quantitation of apoptotic cells by measurement of sub-G1DNA content using the propidium iodide method was carried out as described.

\section{Transient transfection and luciferase activity assays}

HepG2 cells were transiently transfected in triplicate using effect transfection reagent (TaKaRa). Plasmid encoding Renilla luciferase (pTCF/LEF-luc) was transfected for the normalization of transfection efficiency, unless otherwise indicated. Cells are trypsinized and evenly distributed into the wells of a six-well plate prior to designation of treatment condition. 24h after transfection the cells were treated with TSA indifferent concentrations $(250,500 \mathrm{nmol} / \mathrm{L})$, Supernatant were assayed for Renilla luciferase activities using the Luciferase Reporter Assay system reagent (TaKaRa), and assayed according to manufacturer's directions.

\section{HDACs activity}

The activity of total HDACs was detected by HDACs Colorimetric kit. Dilute test samples $(150 \mu \mathrm{g}$ of cell lysate) to $85 \mu 1$ (final volume) of ddH20 in each well (For background reading, add $85 \mu 1 \mathrm{ddH} 20$ only). Add $10 \mu 1$ of the 10X HDAC Assay Buffer to each well. Then add 
$5 \mu 1$ of the HDAC colorimetric substrate to each well. Mix thoroughly. Incubate plates at $37^{\circ} \mathrm{C}$ for $1 \mathrm{~h}$. Stop the reaction by adding $10 \mu 1$ of Lysine Developer and mix well. Incubate the plate at $37^{\circ} \mathrm{C}$ for $30 \mathrm{~min}$. Read sample in an ELISA plate reader at $400 \mathrm{~nm}$.

\section{Western blot analysis}

The protein content of cell extracts was determined by the Bradford assay (Bio-Rad). A total of $20-30 \mu \mathrm{g}$ of protein was electrophoresed on 10-15\% SDS-PAGE gels and transferred to PDVF membranes. Membranes were blocked, incubated with primary Abs at the appropriate concentration, and subsequently incubated with horseradish peroxidase-conjugated goat antirabbit IgG or goat anti-mouse IgG (1:2000 dilutions). Labeled bands were detected by Immun-StarTMHRP Chemiluminescent Kit, and images were captured and the intensity of the Bands was quantified by the Bio-Rad VersaDocTM image system (Bio-Rad, Re-gents Park, NSW, Australia).

Reverse transcription polymerase chain reaction (RTPCR) analysis

Total RNA was extracted using TRIzol Reagent (Invitrogen). Reverse transcription PCR was carried out using MMLV transcriptaseand Oligod (T) and the resulting cDNA products were used as templates for real-time PCR assays. Real-time RT-PCR was performed using the ABI Prism 7700 sequence detection system (PE Applied Biosystems). Twenty-five $\mu 1$ mixture was used for reaction. Fold change in gene expression was determined using the $2-\Delta \Delta \mathrm{CT}$ method with $\beta$-actin as endogenous control. Primer sequences were as follows: $\beta$-catenin:Forward: CGCCAGGG CGCCAGGGTTTTCCCAGTCACGAC. Revers:TAATACGACTCACTAGAGGG. HDAC1:Forw ard:CGCGGATCCACCACCATGGCGCAGACGCAGG GCACCC Revers:CCCAAGCTTTCAGGCCAACTTGA CCTCCACCTTGAC. HDAC3:Forward: CGCGGATCC ACCACCATGGCCAAGACCGTGGCCTATTTCTACG. Revers:TGCTCTAGATTAAATCTCCACATCGCTTTC CTTGTC. After incubation at $5^{\circ} \mathrm{C}$ for $2 \mathrm{~min}$ followed by $95^{\circ} \mathrm{C}$ for $10 \mathrm{~min}$, the reaction was carried out for 40 cycles of the following: $95^{\circ} \mathrm{C}$ for $15 \mathrm{secs}$ and $60^{\circ} \mathrm{C}$ for $1 \mathrm{~min}$.

\section{Immunoflulrescence}

In a word, sterile glass slide placed in 6-well plate, then $1 \times 10^{7}$ cells were seeded. After $24 \mathrm{~h}$, treatment group were added TSA $(250,500 \mathrm{nmol} / \mathrm{L})$, untreatment group were added DMSO, incubate $24 \mathrm{~h}$, fixed with $4 \%$ paraformaldehyde, cell membrane was ruptured by $0.3 \%$ Triton $\mathrm{X}-100$, closed with mountain goat serum (HyClone, Waltham, MA, USA), added antibody $\beta$-catenin (1:100), H3K9 (1:100), respectively. Overnight, anti-rabbit secondary fluorescent antibody was added and incubated for 1h, stained with PI (Beyotime Institute of Biotechnology, Shanghai, China), covered with 50\% glycerol, imaging by fluorescent microscope.

\section{Statistics analysis}

The intensity of the immunoreactive bands was determined by a densitometer (Bio-Rad, Hercules, CA).
Statistical significance of differences between control and treated samples was calculated by Student's t-test (SSPS 17.0). $p<0.05$ were considered significant. All the experiments were repeated at least three times, each time with three or more independent observations.

\section{Results}

\section{Growth studies}

TSA inhibited the survival of HepG2 cells in various concentration ranged from 50 to $500 \mathrm{nmol} / \mathrm{L}$. Compared with the untreated group, cell proliferation was restrained significantly by TSA $(50-500 \mathrm{nmol} / \mathrm{L})$ in treated group $(p<0.01)$. In addition, HepG2 liver cancer cell growth inhibition was dose and time dependent (Figure1A). Shortly after addition of TSA (6-72h) HepG2 cells underwent a remarkable dose-dependent change of cell shape from polygonal to elongated, with cytoplasmatic extensions, differing from microscopic apoptosis. It caused cell morphology changes with numerous floating cells (Figure 1B).

\section{Cell cycle perturbation and apoptosis were induced by TSA}

To elucidate the pharmacological mechanism of TSA, HepG2 cells were treated with TSA in different concentrations. Flow cytometric analysis of the cell cycle revealed that the tested drugs, incubated with HepG 2 cells for $24 \mathrm{~h}$ had strong effects on the cell cycle progression in comparison with untreated cells (Figure 2A). Compared with those in control group, the HepG2 cells after treated with $250 \mathrm{nmol} / \mathrm{L}$ and $500 \mathrm{nmol} / \mathrm{L}$ TSA showed that the percentage in $\mathrm{G} 0 / \mathrm{G} 1$ phase increased from $(51.61 \pm 1.54) \%$ to $(58.35 \pm 1.22) \%$ and $(61.41 \pm 0.94) \%$ respectively; the percentage in $\mathrm{S}$ phase decreased from $(35.31 \pm 0.72) \%$ to $(25.31 \pm 0.96) \%$ and $(17.57 \pm 1.15) \%$ respectively; the percentage in $\mathrm{G} 2 / \mathrm{M}$ phase increased from $(13.07 \pm 1.92) \%$ to $(16.33 \pm 1.81) \%$ and $(21.01 \pm 0.49) \%$ respectively, the difference statistically significant $(\mathrm{F}=19.85, p<0.05)$. TSA could arrest the cell cycle of HepG2 cells in G0/ G1 and G2/M phase. To further explore the underlying mechanisms, we studied the expression of cell cycle associated proteins. We found that TSA decreased the

$\Lambda$
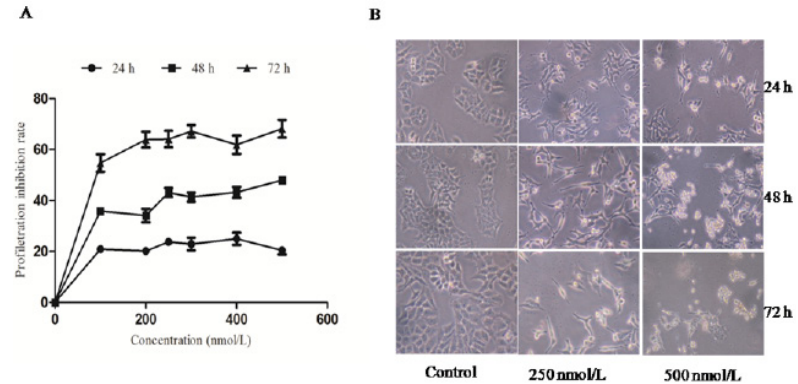

Figure 1. Growth Studies. (A) HepG2 cells were incubated with TSA for $24,48,72 \mathrm{~h}$, and then assessed by the CKK assay. Cell growth was in a dose-dependent manner. Each point represents mean $\pm \mathrm{SD}(\mathrm{n}=6)$. (B) HepG2 cells were incubated with TSA for $24,48,72 \mathrm{~h}$, and cell morphology was observed by inverted microscope and photographed. Results shown was representative of at least three independent experiments. ${ }^{*} p<0.05$ vs control 

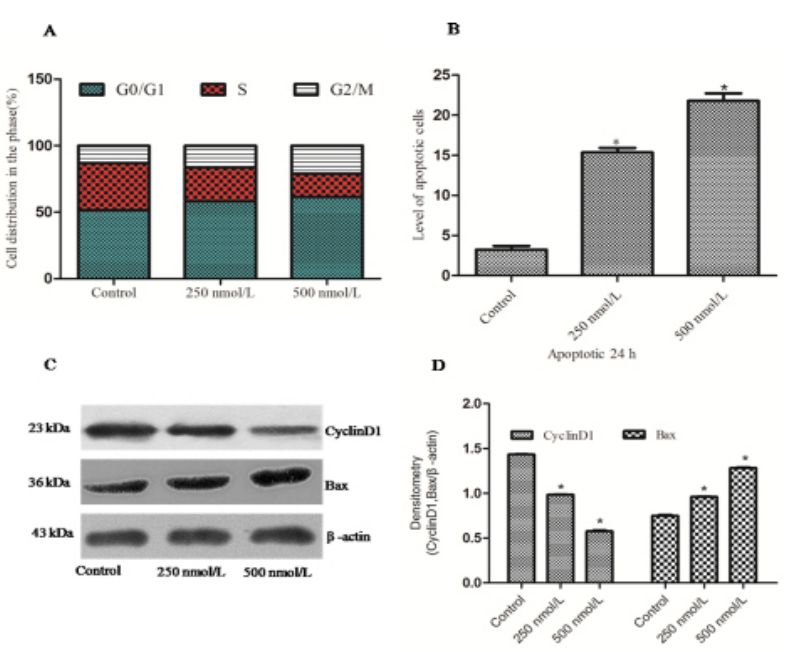

Figure 2. Cell cycle Perturbation and Apoptosis were Induced by TSA. (A) HepG2 cells cycle arrest was induced for $24 \mathrm{~h}$ with TSA $(250,500 \mathrm{nmol} / \mathrm{L})$. Cell cycle distribution was analyzed by flow cytometry. White areas show phase, right red areas show $\mathrm{S}$ phase, and bule areas show G0/G1 phase of the cell cycle. Proportion of cells is expressed as mean \pm SD of three independent experiments. (B) Apoptosis in HepG2 cells treated for $24 \mathrm{~h}$ with TSA $(250,500 \mathrm{nmol} / \mathrm{L})$ was measured by by Annexin V-FTIC/PI. Controls was treated with the appropriate vehicle. Duplicate samples were measured and representative experimental results are shown. (C) HepG2 cells was incubated with TSA $(250,500 \mathrm{nmol} / \mathrm{L})$, expression of CyclinD1,Bax was determined by western bolt, $\beta$-actin served as protein loading control. (D) Densitometry of CyclinD1, Bax/ $\beta$-actin. Results shown was representative of at least three independent experiments. ${ }^{*} p<0.05$ vs control

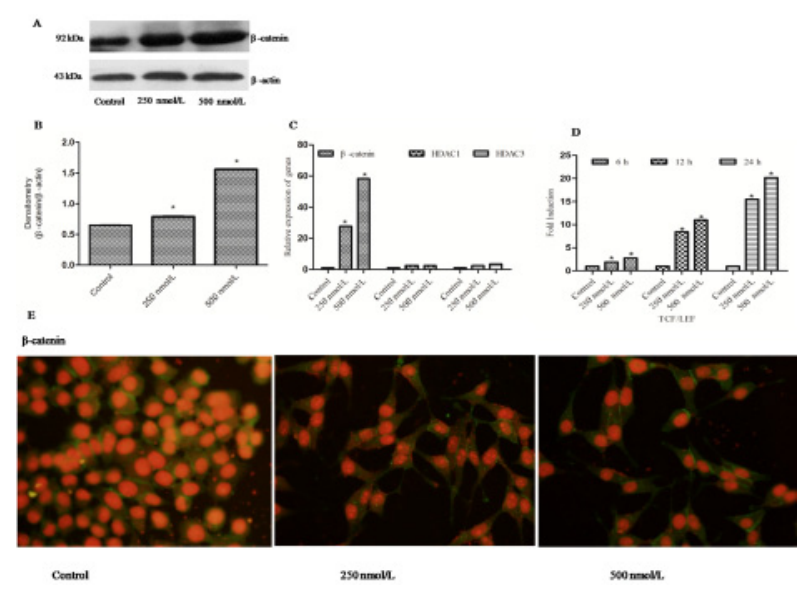

Figure 3. Active Wnt/ק-Catenin Singal Path Way. (A) HepG2 cells were incubated for $24 \mathrm{~h}$ with TSA $(250,500 \mathrm{nmol} / \mathrm{L})$, expression of $\beta$-catenin was determined by western bolt, $\beta$-actin served as protein loading control. (B) Densitometry of $\beta$-catenin/ $\beta$-actin. (C) HepG2 cells were incubated for $24 \mathrm{~h}$ with TSA $(250,500 \mathrm{nmol} / \mathrm{L})$, expression of $\beta$-catenin, HDAC1, HDAC3 genes were measured by qRT-PCR. (D) The cells untreated as control, the cells was transfected with plasmid encoding Renilla luciferase (pTCF/LEF-luc) as treated group with TSA $(250,500 \mathrm{nmol} / \mathrm{L})$. after $6,12,24 \mathrm{~h}$, the Supernatant were assayed for Renilla luciferase activities using the Luciferase Reporter Assay system reagent(TaKaRa), and assayed according to manufacturer's direction. (E) HepG2 cells were incubated for $24 \mathrm{~h}$ with TSA $(250,500 \mathrm{nmol} / \mathrm{L})$, fluorescence microscopy images of $\beta$-catenin expressing in isolated single cell. Results shown was representative of at least three independent experiments. ${ }^{*} p<0.05$ vs control level of CyclinD1 (Figure 2C). The decreased expression of CyclinD1 may be associated with the G2/M cell cycle arrest induced by TSA. Annexin V/PI analysis was performed to confirm the apoptosis function (Figure 2B). The expression of apoptotic mediators Bax was detected by Western blotting after $24 \mathrm{~h}$ of treatment with TSA ( 250 , $500 \mathrm{nmol} / \mathrm{L}$ ). These results suggested that TSA was capable of inducing apoptosis through the intrinsic pathway.

\section{Active wnt $/ \beta$-catenin singal path way}

We examined the change of $\beta$-catenin protein after treatment with TSA. As shown in Figure 3A, after being treated for $24 \mathrm{~h}$ with TSA $(250,500 \mathrm{nmol} / \mathrm{L}) \beta$-catenin protein was up-regulated, and the up-regulation was associated with the concentrations of TSA. In order to further validate up-regulated $\beta$-catenin protein by increasing genes expression, we used quantitative fluorescent PCR to determine $\beta$-catenin genes. The results demonstrated the expression of $\beta$-catenin genes in treated group $(250,500 \mathrm{nmol} / \mathrm{L})$ was up-regulated (Figure $3 \mathrm{C}$ ). Since nuclear $\beta$-catenin was a hallmark of activated WNT/ $\beta$-catenin signaling, we performed Immunofluorescence to determine the localization of $\beta$-catenin to further validate the activation of $\mathrm{WNT} / \beta$-catenin signaling. As shown in Figure 3E, treated cells exhibited strong green fluorescence in the cytoplasm, and small amount of green fluorescence could be visibled in the nucleus. Compared with the control group $\beta$-catenin no obvious changed in the cytoplasm. When it migrates to the nucleus, acts as a co-stimulatory protein for the TCF/LEF family of transcription factors. To further determine the changes due to treatment with TSA in $\beta$-catenin, we next examined activity of TCF transcription factor which dependent on $\beta$-catenin by luciferase reporter assay. Stimulation of TCF reporter activity was found when the cells were treated with TSA, suggesting that TCF-dependent transcriptional activity could be activated by TSA (Figure 3D).

\section{Inhibiting HDACl and HDAC3 enzymes and increasing histone acetylation}

We examined the activity of total HDACs being treated for $24 \mathrm{~h}$ with TSA $(250,500 \mathrm{nmol} / \mathrm{L})$, the activity of total HDACs was down-regulated, and the down-regulated was associated with the concentrations of TSA (Figure 4A). As shown in Figure 4B, after being treated for 24h with TSA $(250,500 \mathrm{nmol} / \mathrm{L}), \mathrm{HDAC} 1$ and HDAC 3 protein was down-regulated, and the down-regulated was associated with the concentrations of TSA. We also determined genes of HDAC1 and HDAC3, compared with control group, the expression of HDAC1, HDAC3 gene had no significant changes (Figure 3C). The histone deacetylases (HDACs) opposed the action of histone acetyltransferases, removing acetyl groups from histone lysine tails, which resulted in chromatin compaction. The expression of $\mathrm{H} 3 \mathrm{~K} 9$ was proved to be up-regulated in manner of concentrations. We performed Immunofluorescence to determine the localization of H3K9 and further validate the histone acetylation was modified by histone deacetylases. As shown in Figure 4D, treated cells exhibited strong green fluorescence in the nucleus, in contrast, the control cells showed weak green fluorescence. 

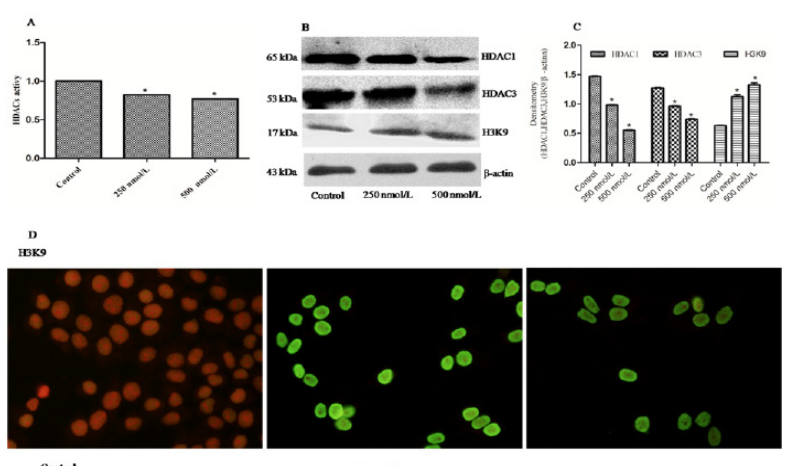

son

(500

Figure 4. Inhibiting HDAC1 and HDAC3 Enzymes and Hitone Acetylation Increased. (A) HepG2 cell be incubated for $24 \mathrm{~h}$ with TSA $(250,500 \mathrm{nmol} / \mathrm{L})$, the activy of total HDACs was detected by HDACs Colorimetric kit. (B) HepG2 cell be incubated for $24 \mathrm{~h}$ with TSA(250, $500 \mathrm{nmol} / \mathrm{L})$, expression of HDAC1, HDAC3, H3K9 was determined by western bolt, $\beta$-actin served as protein loading control. (C) Densitometry of HDAC1, HDAC3, H3K9/ $\beta$-actin. (D) HepG2 cells were incubated for $24 \mathrm{~h}$ with TSA $(250,500 \mathrm{nmol} / \mathrm{L})$, fluorescence microscopy images of $\beta$-catenin expressing in isolated single cell. Results shown was representative of at least three independent experiments. ${ }^{*} p<0.05$ vs control

\section{Discussion}

In this experiment, we also found that the proliferation of HepG2 cells within different concentrations of TSA have been varying degrees inhibited, compared with the control, it has a statistically significant difference.TSA acted on HepG2 liver cancer cell growth inhibition was dose and time dependent (Figure 1A). The microscopic observation showed HepG2 liver cancer cells were induced by TSA in $\mathrm{nmol} / \mathrm{L}$ levels. The changes as followed, cell population decreased significantly, scattered growth, no connection between each other, the refraction was strengthen, cell shape was circular, triangle, polygon and appearing a large number of floating cells (Figure 1B). Flow cytometry test results showed that $250 \mathrm{nmol} / \mathrm{L}$ TSA group of apoptosis rate $(7.17 \pm 0.20) \% ; 500 \mathrm{nmol} / \mathrm{L}$ TSA of group of apoptosis rate $(18.14 \pm 0.42) \%$, significantly higher than the control group $(6.22 \pm 0.25) \%$. The experimental results showed that TSA can inhibit liver cancer cell proliferation and induce apoptosis markedly (Figure 2A and Figure 2B).

The abnormal proliferation of tumor is mainly caused by cell proliferation out of control, and thus inhibiting malignant cell proliferation is the key to regulate tumor development (Iguchi et al., 2007). TSA through the cell cycle to inhibit cell proliferation and development of tumor in leukemia cell lines. Cyclin D1 closely relate to the cell cycle, plays a crucial role in cell cycle G1 phase to $\mathrm{S}$ phase transition. The experimental results showed that down-regulation of the Cyclin D1 was consistent with cell cycle arrest, flow cytometry results and cell proliferation experiment results (Figure 2A and Figure 2C). It indicated that TSA reduced Cyclin D1 to adjust period, thus inhibited cell proliferation.

Histone acetylation and deacetylated modification is one of the key mechanisms of gene transcription regulation (Venturelli et al., 2007; Barbetti et al., 2013). The balance of the two kinds of enzyme activity regulates nucleosome core protein acetylation level and the expression of relating genes in eukaryotic cells. When the HAT and HDAC activity disorder will result in the expression of relating genes out of control (Bai and Merchant, 2007), eventually lead to the occurrence of tumor. Trichostatin A (TSA), derived from the streptomycin metabolites, was first used as antifungal drugs (Herold et al., 2002). In recent years, research has shown that it is histone acetylation enzyme inhibitors (HDACi), specifically to inhibit I, II class histone acetylation enzyme (HDACs) activity. TSA can accumulate the acetylation of histone, change the chromosome structure, inhibit cell proliferation, induce tumor cell differentiation or apoptosis, and is a kind of new type anti-tumor drugs that has a broad prospect and targeted, but its mechanism remains to be further clarified. Studies found that the TSA obviously inhibited proliferation and promoted apoptosis in a wide variety of tumor. In this experiment, the activity of total HDACs was down-regulated, and the down-regulated was associated with the concentrations of TSA, and western blotting results demonstrated that histone acetylation enzyme HADC1, HDAC3 significantly decreased in dosing group with concentration increasing, compared with the control group (Figure 4B). Then we checked histone $\mathrm{H} 3 \mathrm{~K}$ 9, the acetylation level was on the rise (Figure 4B). Histone acetylation neutralize positive charge of histone, making mutually exclusive between the histone and the negatively charged DNA phosphate skeleton, the result is chromatin structure loosing chromatin, which is beneficial to $\beta$-catenin touching with TCF, and transcription factors, transcription complex, RNA polymerase is more close to the DNA promoter regions, stimulating downstream gene translation, including Bax, Bcl-2, P2I, P53, inducing cycle arrest and apoptosis (Feng et al., 2013).

According to previous reports, the constitutive activation of $\mathrm{WNT} / \beta$-catenin signaling is believed to promote cell proliferation and tumorigenesis in tissues including the colon and the pancreas. However, the role of $\mathrm{WNT} / \beta$-catenin signaling is multifaceted in human cancer cells. Interestingly, augmentation of $\mathrm{WNT} / \beta$ catenin was found to be associated with the anti-tumor effects of HDACis in both colon cancer and pancreatic cancer (Shao et al., 2012). It is generally believed that $\mathrm{WNT} / \beta$-catenin signaling is constitutively activated in HepG2, and the aberrant activation of WNT/ $\beta$-catenin signaling is associated with Hepatic carcinoma (Cui et al., 2001). However, to date, there has been no study of the effects of HDACis on WNT/ $\beta$-catenin signaling in HepG2. Thus, we treated human HepG 2 cells with HDACis, TSA, and analyzed the subsequent effects on WNT/ $\beta$-catenin signaling as well as anti-tumor effects against HepG2 cells. We have proved that TSA induce growth inhibition, apoptosis and cell cycle arrest in HepG2 cell lines. More importantly, we have demonstrated, to the best of our knowledge for the first time, that $\mathrm{WNT} / \beta$-catenin signaling is strengthened by HDACis, and mediates the anti-tumor effects of HDACis against HepG2.

Recent studies have shown that transcriptional activity of $\mathrm{Wnt} / \beta$-catenin signaling pathway was able to adjust by histone acetylation enzyme inhibitors, indicating Wnt/ $\beta$ catenin signaling pathway may be potential of nonhistones 
Qing-Qiang Shi et al

targets (Dahmani et al., 2011). In experiment, we found that the TSA played a role of anti-tumor accompanied by $\beta$-catenin protein expression. When chromatin is in a state of relaxation conditions, $\beta$-catenin can combine with TCF in the nucleus. After combination, $\mathrm{N}$ - and $\mathrm{C}$ - the end of $\beta$-catenin exposure, HAT protein CBP and p300 interact with $\beta$-catenin $\mathrm{R} 10-\mathrm{C}$ area, promoting the cofactor recruit, activating some transcription of Wnt target genes, such as Bax, Bcl-2, P2I, P53, thus inhibiting hepatocellular carcinoma cell proliferation and promoting apoptosis of HepG2 (Mosimann et al., 2009). We detected Bax protein, increased in TSA treated group. At the same time TSA promoted the apoptosis of HepG2 cells (Figure 2C).

TSA can inhibit the activity of HDAC, promote the histone acetylation and, activate $\mathrm{Wnt} / \beta$-catenin signaling pathway to inhibit the proliferation of HepG2 cell, inducing cycle arrest and apoptosis.

\section{Acknowledgements}

This research was supported by the grants from the National Natural Science Foundation of China (No. KJ130312) and (No.81171929). The authors would like to acknowledge college of Life Science for technical support.

\section{References}

Bai L, Merchant JL (2007). A role for CITED2, a CBP/p300 interacting protein, in colon cancer cell invasion. FEBS Letters, 581, 5904-10.

Barbetti V, Gozzini A, Cheloni G, et al (2013). Time- and residue-specific differences in histone acetylation induced by VPA and SAHA in AML1/ETO-positive leukemia cells. Epigenetics, 8, 210-9.

Chen W-Q, Xu B, Mao J-W, et al (2014). Inhibitory effects of $\alpha$-pinene on hepatoma carcinoma cell proliferation. Asian Pac J Cancer Prev, 15, 3293-7.

Cui J, Zhou X, Liu Y, et al (2001). Mutation and overexpression of the $\beta$-catenin gene may play an important role in primary hepatocellular carcinoma among Chinese people. J Cancer Res Clin Oncol, 127, 577-81.

Dahmani R, Just PA, Perret C (2011). The Wnt/ $\beta$-catenin pathway as a therapeutic target in human hepatocellular carcinoma. Clin Res Hepatol Gastroenterol, 35, 709-13.

Debeb BG, Lacerda L, Xu W, et al (2012). Histone deacetylase inhibitors stimulate dedifferentiation of human breast cancer cells through WNT/ $\beta$-catenin signaling. Stem Cells, 30, 2366-77.

Feng D, Wu J, Tian Y, et al (2013). Targeting of histone deacetylases to reactivate tumour suppressor genes and its therapeutic potential in a human cervical cancer xenograft model. PLoS One, 8, 80657-68.

Fujisawa K, Maesawa C, Sato R, et al (2005). Epigenetic status and aberrant expression of the maspin gene in human hepatobiliary tract carcinomas. Lab Invest, 85, 214-24.

Haghshenas MR, Arabi M, Mousavi T (2014). Hepatitis B genotypes in iran. Mater Sociomed, 26, 129-33.

Herold C, Ganslmayer M, Ocker M, et al (2002). The histonedeacetylase inhibitor Trichostatin A blocks proliferation and triggers apoptotic programs in hepatoma cells. J Hepatol, 36, 233-40.

Iguchi H, Urashima Y, Inagaki Y, et al (2007). SOX6 suppresses cyclin D1 promoter activity by interacting with $\beta$-catenin and histone deacetylase 1 , and its down-regulation induces pancreatic $\beta$-cell proliferation. J Biol Chem, 282, 19052-61.

Ji Z, Wang T, Shao Z, et al (2014). A population-based study examining hepatitis $\mathrm{B}$ virus infection and immunization rates in Northwest China. PLoS One, 9, 97474-84.

Ker CG, Chen JS, Kuo KK, et al (2011). Liver surgery for hepatocellular carcinoma: laparoscopic versus open approach. Int J Hepatol, 2011, 596792.

Lazarova DL, Bordonaro M, Carbone R, et al (2004). Linear relationship between Wnt activity levels and apoptosis in colorectal carcinoma cells exposed to butyrate. Int J Cancer, 110, 523-31.

Lee JE, Bae SH, Choi JY, et al (2014). Epirubicin, cisplatin, 5-FU combination chemotherapy in sorafenib-refractory metastatic hepatocellular carcinoma. World J Gastroenterol, 20, 235-41.

Li J-P, Cao N-X, Jiang R-T, et al (2014). Knockdown of GCF2/ LRRFIP1 by RNAi causes cell growth inhibition and increased apoptosis in human hepatoma HepG2 cells. Asian Pac J Cancer Prev, 15, 2753-8.

Marks P, Rifkind RA, Richon VM, et al (2001). Histone deacetylases and cancer: causes and therapies. Nat Rev Cancer, 1, 194-202.

Miyahara K, Nouso K, Yamamoto K (2014). Chemotherapy for advanced hepatocellular carcinoma in the sorafenib age. World J Gastroenterol, 20, 4151-9.

Miyoshi H, Deguchi A, Nakau M, et al (2009). Hepatocellular carcinoma development induced by conditional $\beta$-catenin activation in Lkb1+/- mice. Cancer Sci, 100, 2046-53.

Mosimann C, Hausmann G, Basler K (2009). Beta-catenin hits chromatin: regulation of Wnt target gene activation. Nat Rev Mol Cell Biol, 10, 276-86.

Myzak MC, Karplus PA, Chung FL, et al (2004). A novel mechanism of chemoprotection by sulforaphane: inhibition of histone deacetylase. Cancer Res, 64, 5767-74.

Osaki A, Suda T, Kamimura K, et al (2013). A safe and effective dose of cisplatin in hepatic arterial infusion chemotherapy for hepatocellular carcinoma. Cancer Med, 2, 86-98.

Page AJ, Cosgrove DC, Philosophe B, et al (2014). Hepatocellular carcinoma: diagnosis, management, and prognosis. Surg Oncol Clin N Am, 23, 289-311.

Pathil A, Armeanu S, Venturelli S, et al (2006). HDAC inhibitor treatment of hepatoma cells induces both TRAILindependent apoptosis and restoration of sensitivity to TRAIL. Hepatology, 43, 425-34.

Quint K, Agaimy A, Di Fazio P, et al (2011). Clinical significance of histone deacetylases $1,2,3$, and 7: HDAC2 is an independent predictor of survival in HCC. Virchows Arch, 459, 129-39.

Scaggiante B, Kazemi M, Pozzato G, et al (2014). Novel hepatocellular carcinoma molecules with prognostic and therapeutic potentials. World J Gastroenterol, 20, 1268-88.

Shao N, Zou J, Li J, et al (2012). Hyper-activation of WNT/ $\beta$ catenin signaling pathway mediates anti-tumor effects of histone deacetylase inhibitors in acute $\mathrm{T}$ lymphoblastic leukemia. Leuk Lymphoma, 53, 1769-78.

Song W-F, Wang L, Huang W-Y, et al (2013). MiR-21 upregulation induced by promoter zone histone acetylation is associated with chemoresistance to gemcitabine and enhanced malignancy of pancreatic cancer cells. Asian Pac $J$ Cancer Prev, 14, 7529-36.

Tanase A-M, Dumitrascu T, Dima S, et al (2014). Influence of hepatitis viruses on clinico-pathological profiles and long-term outcome in patients undergoing surgery for hepatocellular carcinoma. Hepatobiliary Pancreatic Dis Int, 13, 162-72.

Thompson MD, Monga SP (2007). WNT/ $\beta$-catenin signaling in liver health and disease. Hepatology, 45, 1298-305. 
Tsai WL, Lai KH, Liang HL, et al (2014). Hepatic arterial infusion chemotherapy for patients with huge unresectable hepatocellular carcinoma. PLoS One, 9, 92784.

Venturelli S, Armeanu S, Pathil A, et al (2007). Epigenetic combination therapy as a tumor-selective treatment approach for hepatocellular carcinoma. Cancer, 109, 2132-41.

Wiltse J (2005). Mode of Action: Inhibition of histone deacetylase, altering WNT-dependent gene expression, and regulation of beta-catenin-developmental effects of valproic acid. Crit Rev Toxicol, 35, 727-38.

Woo HJ, Lee SJ, Choi BT, et al (2007). Induction of apoptosis and inhibition of telomerase activity by trichostatin A, a histone deacetylase inhibitor, in human leukemic U937 cells. Exp Mol Pathol, 82, 77-84.

Xu L-B (2010). Staging systems for predicting survival of patients with hepatocellular carcinoma after surgery. World Journal of Gastroenterology, 16, 5257.

Yang XJ, Seto E (2007). HATs and HDACs: from structure, function and regulation to novel strategies for therapy and prevention. Oncogene, 26, 5310-8.

Ying Y, Tao Q (2009). Epigenetic disruption of the WNT/ $\beta$ catenin signaling pathway in human cancers. Epigenetics, 4, 307-12.

Zhang Q-C, Jiang S-J, Zhang S, et al (2012). Histone deacetylase inhibitor trichostatin a enhances antitumor effects of docetaxel or erlotinib in A549 cell line. Asian Pac J Cancer Prev, 13, 3471-6. 